Article

\title{
Transportation Services for Older Adults and Preventive Healthcare Attainment
}

\author{
Zeenat Kotval-K ${ }^{1, *(\mathbb{D})}$, Linda Keilman ${ }^{2}$ and Weijing Wang ${ }^{1}$ \\ 1 School of Planning, Design \& Construction, Michigan State University, East Lansing, MI 48824, USA; \\ wangwe92@msu.edu \\ 2 College of Nursing, Michigan State University, East Lansing, MI 48824, USA; keilman@msu.edu \\ * Correspondence: kotvalze@msu.edu; Tel.: +1-517-353-5460
}

Received: 29 July 2020; Accepted: 19 August 2020; Published: 22 August 2020

\begin{abstract}
This study examines the impact of the provision of specialized transportation services for older adults on the attainment of preventive healthcare services in selected cities across Michigan. The main hypothesis is that transportation services are critical factors for older adults to not only attain preventive healthcare but also to maintain an active lifestyle that avoids the physical, mental and social isolation that they may face when advised to stop driving. Results indicate that provision of transit services and socio-economic characteristics have statistically significant effects on the attainment of preventive healthcare services. However, although transportation is a critical element for maintaining medical appointments, other factors need to be considered if we truly want to attain better health outcomes for all older adults. Qualitative analyses point to other logistical barriers and the need for more awareness of insurance plans and covered services in order to increase preventive healthcare attainment.
\end{abstract}

Keywords: older adults; preventive health; transportation services

\section{Introduction}

In the United States, the demographical structure has witnessed a significant increase in the size and proportion of the elderly population. According to data released by the U.S. Census Bureau, the population aged 65 years old above will increase at an even greater rate in the coming decades. Compared to the whole country, the state of Michigan has experienced a higher rate of population ageing. Statistical data show that in 2017, 15.9 percent of the population in Michigan was aged 65 and over, 1.9 percent higher than the rate for the whole country [1]. This rapid growth of the elderly population in Michigan brings new challenges to social systems, including transportation networks in this ageing society. The older population have decreasing physical and mental conditions as they reach retirement age. This consequently results in an increase in the need for healthcare and visits to doctors' offices. Prior studies suggest that the provision of specialized transit services for the elderly population is closely related to the attainment of healthcare access and health outcomes. This unprecedented growth of the elderly population and their decreasing health conditions bring new challenges to the current transportation system. Scholarly literature suggests that for the population aged 65 and above who cease to drive, the need to use specialized transit services such as paratransit or senior vans increases as people become older [2]. Therefore, evaluating the current specialized transit services for the elderly population provides primary suggestions for transportation professionals and planners to improve the current transit system to serve the older population. This has inspired and framed our study.

Our study aims to examine the relationship between the provision (and aspects related to the provision) of specialized transit services for the elderly population (i.e., population aged 65 and 
above) and the attainment of preventive healthcare services. We undertake a mixed methods approach by utilizing secondary data from the 500 Cities Project and primary data from stakeholders and transit agencies to conduct a census tract level analysis in sixteen cities across the state of Michigan.

\section{Literature Review}

\subsection{Elderly Population and Transit Needs}

Population ageing has become a vital issue not only in the United States but also in most countries around the world. The population who are aged 65 and above (older adults) in the U.S. has increased at a rapid rate. Between 2000 and 2010, the number of people who are aged 65 and above increased from 34.99 million to 40.27 million [1]. Seven years later, this number reached 47.73 million in 2017, which accounts for 14.0 percent of the total population of the country [1]. Similarly, the state of Michigan has witnessed rapid growth of its elderly population in the last couple of decades. In 2017, the number of the population who were aged 65 and above equaled 1.58 million, which accounts for 15.9 percent of the total population of the state. This statistical data reveals that the state of Michigan has a larger proportion of elderly citizens (15.9 percent in Michigan) compared with the country (14.0 percent in the U.S.). This increasing growth in the size of the population aged 65 and above brings new challenges to support systems such as healthcare facilities and transportation systems.

Many older adults have an increasing transportation needs for medical appointments due to their decreasing physical and mental conditions at retirement age $[3,4]$. One prominent purpose of visiting doctors' offices is to attain preventive healthcare as people age. One study found that among the 163,277 medical appointments collected in Delaware, 99.8 percent are non-emergent requests [3]. Another conducted a questionnaire interview study in Taiwan to examine the health conditions of the elderly population [4]. The results analyzed from 4249 respondents who are aged 50 and above show that 71.7 percent of them have one or more chronic diseases [4]. This large number of non-emergent medical requests among the elderly population, combined with the large proportion of the elderly population who have chronic diseases, increases transit needs so that people can access doctors' offices and attain preventive healthcare.

\subsection{Current Transit System and Barriers for the Elderly}

Decreasing health conditions and increasing transportation needs for healthcare purposes among older adults bring new challenges to current transit systems. It is well-known that the private automobile is the dominant way to make daily trips in the United States, specifically in Michigan. Not surprisingly, elderly citizens also have a strong preference to drive around and maintain their independence [2]. However, many elderly citizens are advised to stop driving due to their decreasing physical and mental conditions. Also, the financial constraints people face as they reach retirement age reduces their possibility of owning a private vehicle and driving independently. More importantly, driving independently to medical appointments might not be appropriate, and might even be dangerous, when people experience physical or mental challenges or difficulties. Prior studies found that holding a driving license is significantly related to the attainment of healthcare [5]. The studies show that chronic care appointments among people who hold a driving license are 2.29 times higher than among people who do not [5]. In addition, giving up driving increases the possibility of missing or delaying chronic care trips, and the lack of door-to-door service and awareness of available transit service raises problems when it comes to using current transit systems for medical appointments for older adults [6]. These findings suggest that giving up driving independently as people age could result in a decrease of healthcare attainments for this population.

Public transit is one substitute that allows older adults to attain preventive healthcare services after they cease to drive, allowing them to remain independent. A higher quality public transit service does provide an additional option for older adults to access healthcare facilities and achieve regular medical appointments [2,7]. A study by Kim suggests that a higher percentage of the older population 
who live in neighborhoods where public transit is accessible within 10 min walking time use these services [2]. However, public transit systems in some areas, especially in the Midwestern United States, are poorly designed and under-provided. The author conducted a spatial analysis study at block level to examine the current transit services provided specifically for the elderly population in the Lansing-East Lansing areas in the state of Michigan [8]. Her study suggests that only 31 percent of blocks that accommodate ten percent or larger of residents who are aged 65 and above are located within reasonable walking distance for the elderly population (183 $\mathrm{m}$ or $600 \mathrm{feet}$ ) in the Lansing-East Lansing areas. With respect to transit stops, only ten percent of bus stops offer benches with covered shelters, adding to the stressors that come with accessing public transit for older adults [8]. In addition, Thakuriah, et al. conducted case studies in the selected seven locations in the United States where the New Freedom Program (i.e., a program designed to fund transportation services for the elderly) is implemented. These scholars analyzed questionnaires from 149 respondents who are aged 65 and above and found that the population aged 85 and above face significant challenges when it comes to using public transit services [9]. Overall, prior findings suggest that current public systems are less suitable for the elderly population when it comes to attaining preventive healthcare services.

When older adults are no longer eligible to drive independently or have difficulty accessing public transit services, seeking a ride from their social network becomes a preferable approach $[2,5,6,10]$. Arcury, Preisser, Gesler, and Powers conducted a survey study in North Carolina to examine the association between transportation accessibility and healthcare attainment in rural regions. The analysis for the data from 1059 households in their study suggests that people who obtain transportation assistance from family or friends have 1.58 times more appointments for chronic care compared with their counterparts who do not [5]. A study by Battista, Lee, Kolodinsky, and Heiss suggests that obtaining assistance from family members is greatly beneficial for the non-driving population to maintain regular medical trips [10]. However, getting a ride for the elderly population from their social network highly depends on the schedule and willingness of family members, friends, or volunteers, which significantly reduces the independence of older adults. Analysis of a telephone survey dataset collected by the American Association of Retired Persons (AARP) in 2014 shows that 63.0 percent of respondents (192 out of 305) reported that they would prefer to get a ride from friends or family when they give up driving [2]. The studies referred to here suggest that current transit systems are not appropriately designed to serve the elderly population, and transit services specifically for this population segment are under-supplied.

\subsection{Transit Services for the Elderly and Healthcare Attainment}

To investigate the impact of transit services on healthcare, previous literature suggests that the provision of transit services is closely related to the attainment of preventive healthcare services as well as health outcomes $[4,6,11,12]$. An interview study conducted in a suburban area in New York suggests that 24 percent (192 out of 698) of clinic visitors aged 18 years old and above reported rescheduling or missing healthcare appointments due to transportation difficulties [11]. Turing to older adults, a study conducted a comprehensive analysis for the 2002 National Health Interview Survey (NHIS). The results show that nearly 3.6 million Americans missed at least one trip to health facilities in one year due to transportation concerns, and of these residents who missed medical trips, more than 16 percent of them were aged 70 and above [12].

Service hours, reliability, and transit costs are frequently cited transportation-related factors of missing healthcare appointments. A study by Mattson (2011) shows that 32 percent of respondents (172 out of 543) identified having problems using public transit to attain chronic care services, and commonly reported problems include inconvenient schedules and infrequent services [6]. Transit service hours are related to a larger number of chronic diseases and a fewer number of trips to pharmacies as well [4]. In terms of transit cost, Wallace et al.'s study suggests that high transit cost is one of contributors to missing medical trips [12]. Kullanit and Taneepanichskul conducted face-to-face interviews to investigate the effects of transportation barriers on healthcare attainment among the population aged 60 
and above in the Mahasarakham province, Thailand [13]. Their analysis suggests that transit expense has a strong impact on the attainment of healthcare among the population [13]. Similarly, a study conducted in northern Manhattan, New York, suggests that lower travel cost increases the accessibility of healthcare services [14].

Additional evidence provided in prior research also emphasizes the close association between distance, accessibility to transportation and healthcare facilities, and the attainment of preventive healthcare services. One of the studies found that rural communities in Vermont have a more serious issue of healthcare accessibility for the elderly population because of the lower supply of healthcare facilities and larger distances to them in general [10]. Another found that the elderly population who live in suburban areas tend to have a low level of accessibility to healthcare due to low density and distribution of health facilities [15]. In addition, travel distance between home and healthcare facilities is another factor that reduces the possibility of healthcare attainment, especially in rural areas $[3,6]$. Smith et al. conducted a study to compare non-emergency medical transportation needs in rural and urban areas in Delaware and found that the round-trip distance for medical appointments in rural areas (25.41 miles) is much longer than urban areas (13.0 miles). The study also suggests that rural areas accommodate a larger percentage of the population aged 75 and above (20.0 percent) compared with urban areas (13.5 percent) in Delaware [3]. This large proportion of the elderly population in rural areas combined with low accessibility to healthcare facilities further aggregate challenges to the attainment of preventive healthcare services in an ageing society.

\subsection{Socio-Economic Characteristics and Healthcare Attainment}

Several prior studies suggest that socio-economic characteristics is another factor that affects the attainment of preventive healthcare services. Some studies suggest that the utilization of transit services among the elderly is related to their health conditions and living arrangement (e.g., living alone) $[6,9]$. To investigate how transportation services impact healthcare access and health outcomes in the United States, a study conducted a review of 61 relevant peer-review studies. The results show that people who are part of disadvantaged population groups such as low income, uninsured, or non-white residents, have a higher rate of traffic barriers to access healthcare compared to their counterparts [16]. Analyzing the 2002 National Health Interview Survey (NHIS), a study found that among the 3.6 million individuals who missed trips to health facilities, almost 55 percent of them have household incomes less than $\$ 20,000$ per year, and near 35 percent are non-white residents [12]. Another study used a dataset from the Barriers to Access to Care for Ethnic Minority Seniors (BACEMS) and found that ethnic minority elderly people have low accessibility to healthcare services in Vancouver, British Columbia [17]. In addition, a study conducted in Montreal Island, Canada, suggests that a lower car ownership rate among the elderly population significantly reduced the accessibility to healthcare facilities [15].

Overall, prior literature suggests that the disadvantaged population such as low-income, non-white, uninsured residents, or people who do not own a car have more difficulties accessing transit services and attaining preventive healthcare services. However, focus on older adults, their access to specialized transportation services, and the resulting impacts on attaining healthcare is underrepresented in the literature. Knowing the generic issues that arise in terms of access to transportation, socio-economic characteristics of residents, and attainment of healthcare, this study delves into transportation issues faced specifically by older adults when accessing healthcare within urban and rural settings.

\section{Materials and Methods}

We use a mixed-methods framework of analysis in this study. We first employ quantitative methods (i.e., regression analysis) to gauge whether significant relationships exist between transportation provision, socio-economic characteristics, and healthcare attainment. Thereafter, we engage qualitative methods (i.e., interviews) with select key informants to get their opinions on the barriers older adults face when fulfilling medical appointments. This section begins with an introduction of the study sites. 
We then provide the data sources, the measurement of variables, and the regression model used in the analysis.

\subsection{Study Areas}

This study is conducted in sixteen cities across the state of the Michigan. One prominent reason for choosing these cities is that data for preventive healthcare attainment among the elderly population are available in the 500 Cities Project. We map the geographical locations of these sixteen cities in Figure 1, which include Livonia, Troy, Ann Arbor, Rochester Hills, Wyoming, Farmington Hills, Grand Rapids, Westland, Sterling Heights, Dearborn, Warren, Kalamazoo, Southfield, Lansing, Flint, and Detroit. Figure 2 shows the percentages of older adults in these study cities that have attained preventive healthcare.
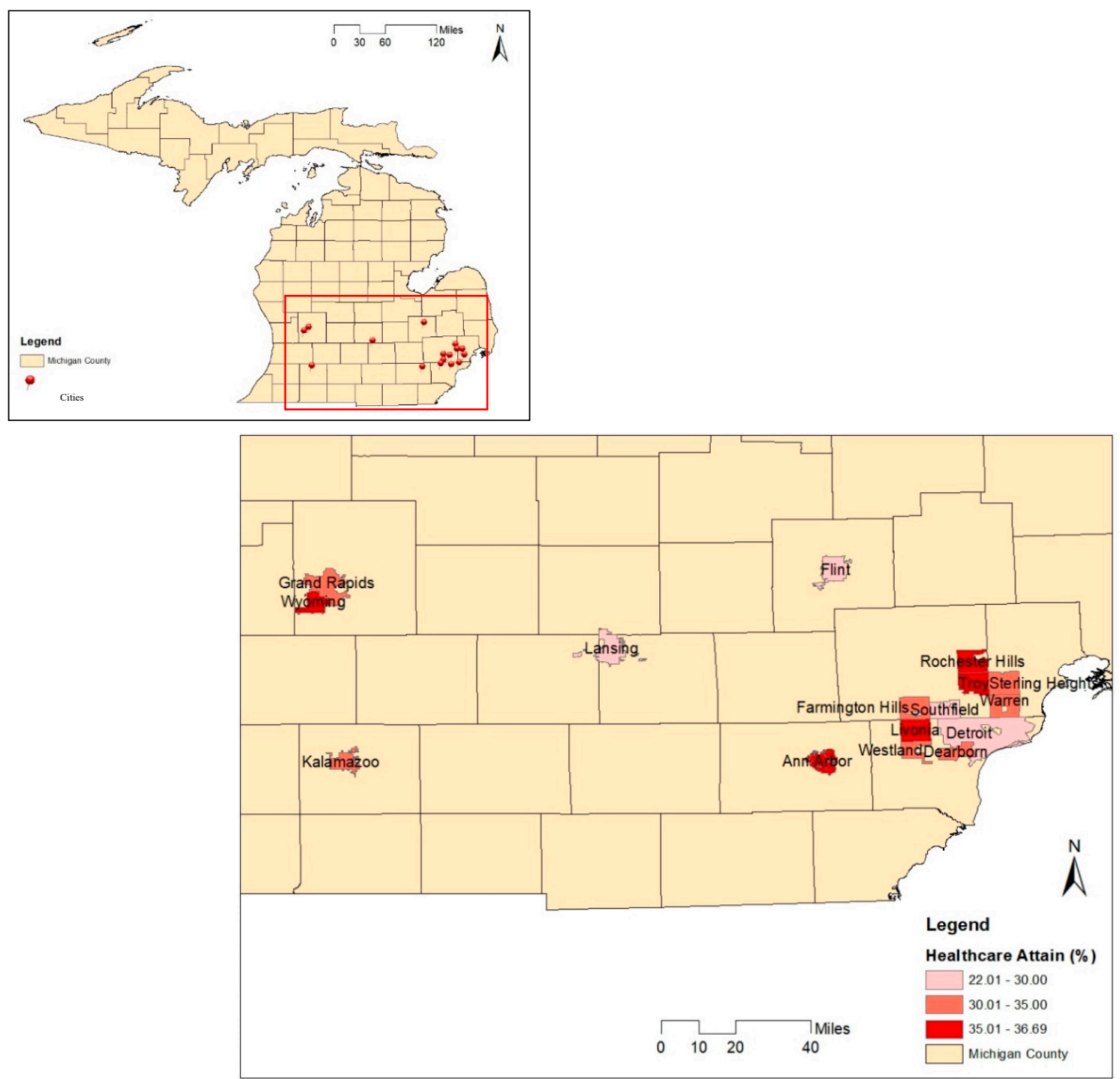

Figure 1. Locations of the selected study cities in Michigan and levels of preventive healthcare attainment amongst older adults. 


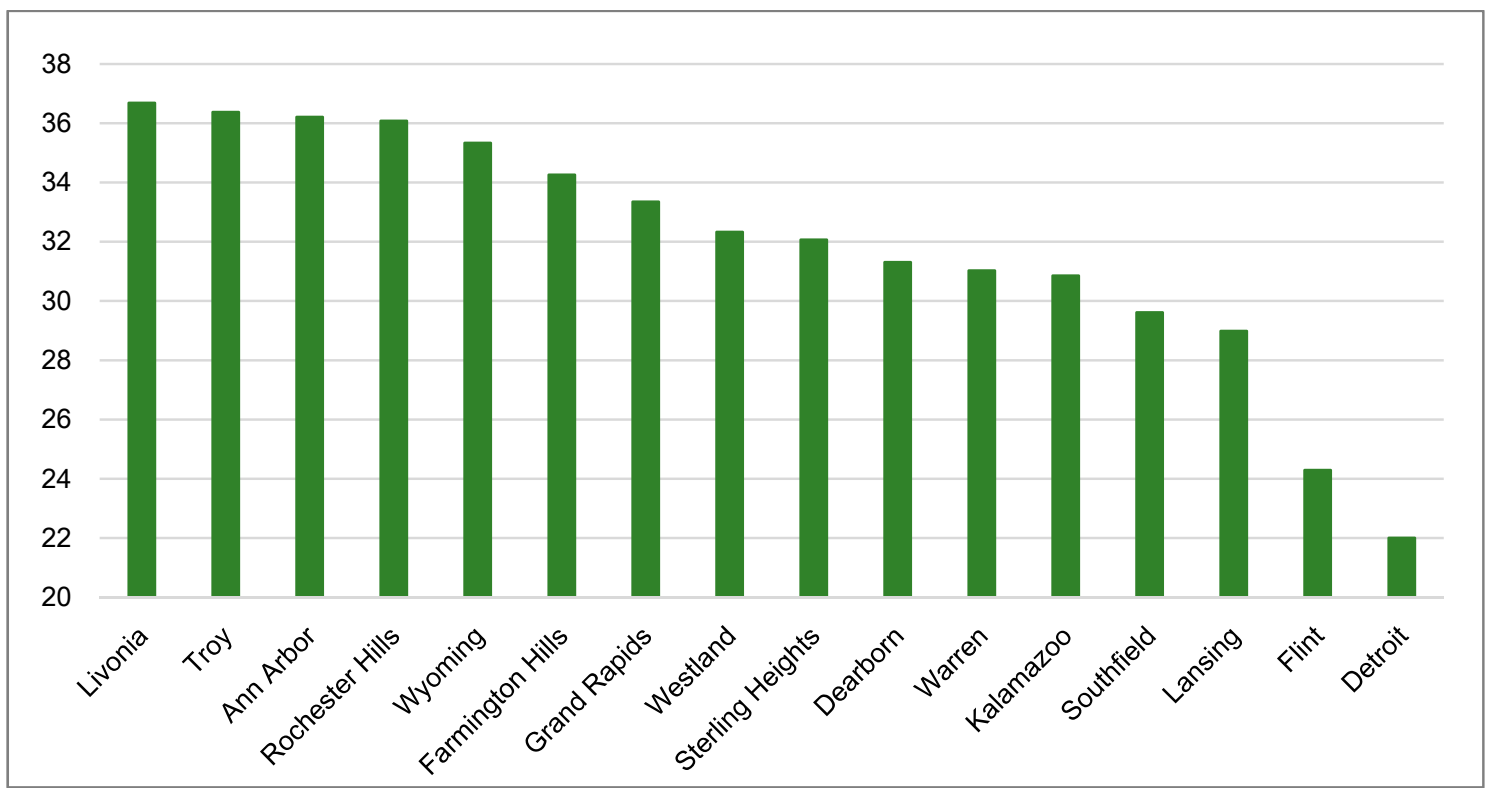

Figure 2. Population aged 65 years old and above who attain preventive healthcare services (\%). (Data Source: 500 Cities Project).

\subsection{Quantitative Analysis}

To construct the final dataset for statistical regression analysis, three public data sources are used in this study: (1) 500 Cities Project, (2) Transit Agency Websites, and (3) U.S. Census. The 500 Cities Project is "a public dataset that provides estimates for chronic disease risk factors, health outcomes, and clinical preventive service use at the city and tract level for the largest 500 cities in the United States" [18]. This new and unique dataset is the first of its kind to provide health data at geographic levels down to census tracts. Research in social sciences has not had such access to health data before, and thus we are now able to conduct empirical and statistical analyses to test our hypotheses. This study measures the dependent variable (i.e., preventive healthcare attainment among the elderly population) as the percentage of the population aged 65 and above who attain clinical preventive services. Figure 1 indicates the locations and percentages of the elderly population who attain preventive healthcare for the selected sixteen cities in Michigan. We chose this as the dependent variable for a couple reasons. First, most of the variables in the 500 Cities database are calculated for adults aged 18 years and above, and only a few variables are available for older adults specifically. Second, preventive healthcare attainment (i.e., regular doctors' appointments) has been a factor of concern when dealing with the lack of transportation for older adults and the impacts this generates.

In terms of the independent variables, the transit agency website for each city provides parameters for the current transportation that specifically serves the elderly population. We first looked over the transit agency websites in the selected cities, and then created a matrix to record transportation-related information. Detailed information about the provision of specialized transit services for the older adult population in each city is listed in Table 1 . The variables utilized in this study to indicate the provisions of current transit services for the older adult population include eligibility requirements (e.g., served area, age, disability, etc.), application procedure to use the services (i.e., advanced reservation and same-day ride), service fees, service types (i.e., door-to-door, curb-to-curb, and wheelchair accessibility), and service hours. 
Table 1. Current specialized transit services for the elderly by cities.

\begin{tabular}{|c|c|c|c|c|c|c|c|c|}
\hline \multirow{2}{*}{ City Name } & \multirow{2}{*}{$\begin{array}{c}\text { Services Program } \\
\text { Name }\end{array}$} & \multirow{2}{*}{$\begin{array}{c}\text { Area } \\
\text { Served }\end{array}$} & \multirow{2}{*}{$\begin{array}{c}\text { Advanced } \\
\text { Notice } \\
\text { Needed } \\
\end{array}$} & \multirow{2}{*}{$\begin{array}{l}\text { Same-Day } \\
\text { Ride }\end{array}$} & \multirow{2}{*}{$\begin{array}{l}\text { Service } \\
\text { Fees/\$ }\end{array}$} & \multirow{2}{*}{$\begin{array}{l}\text { Door to } \\
\text { Door } \\
\text { Services }\end{array}$} & \multicolumn{2}{|c|}{ Service Times } \\
\hline & & & & & & & Monday to Friday & Saturday \& Sunday \\
\hline Ann Arbor & $\begin{array}{c}\text { GoldRide } \\
\text { (Shared-ride trips) }\end{array}$ & City & $\mathrm{Y}$ & Y & 3.5 & $\mathrm{Y}$ & 6:30 a.m.-11:45 p.m. & $\begin{array}{l}\text { Sat. 7:30 a.m.-10:45 p.m., and } \\
\text { Sun. } 8 \text { a.m.-7:45 p.m. }\end{array}$ \\
\hline Dearborn & $\begin{array}{l}\text { Dearborn Senior } \\
\text { Citizen } \\
\text { Transportation }\end{array}$ & City & Y & $\mathrm{N}$ & 1 & $\mathrm{~N}$ & 8:30 a.m.-3:30 p.m. & Closed \\
\hline Detroit & Smart Connector & City & $\mathrm{Y}$ & $\mathrm{N}$ & 1 & $\mathrm{~N}$ & 6:00 a.m.-6:00 p.m. & Closed \\
\hline $\begin{array}{l}\text { Farmington } \\
\text { Hills }\end{array}$ & $\begin{array}{c}\text { Farmington Hills } \\
\text { Senior } \\
\text { Transportation }\end{array}$ & City & $\mathrm{Y}$ & $\mathrm{N}$ & 2 & $\mathrm{~N}$ & 9:00 a.m.-3:30 p.m. & Closed \\
\hline Flint & Your Ride & City & Y & $\mathrm{Y}$ & 2.25 & $Y$ (request) & 6:30 a.m.-10:30 p.m. & $\begin{array}{l}\text { Sat. 6:30 a.m.-10:30 p.m. and } \\
\text { Sun. 7:00 a.m.-7:30 p.m. }\end{array}$ \\
\hline Grand Rapids & Ridelink & City & $\mathrm{Y}$ & $\mathrm{Y}$ & 2 & $\mathrm{Y}$ & 7:30 a.m.-4:30 p.m. & Sun. 8:00 a.m.-2:00 p.m. \\
\hline Kalamazoo & Metro Connect & City & Y & $\mathrm{Y}$ & 4 & $Y$ (request) & 6:00 a.m. to $12: 15$ a.m. & $\begin{array}{l}\text { Sat. 6:00 a.m.-10:15 p.m. and } \\
\text { Sun. 8:00 a.m.-6:00 p.m. }\end{array}$ \\
\hline Lansing & Spec-Tran & $\begin{array}{l}\frac{3}{4} \text { of } \\
\text { a mile on } \\
\text { CATA's } \\
\text { fixed } \\
\text { routes }\end{array}$ & Y & $\mathrm{N}$ & 2.5 & $\mathrm{~N}$ & 5:40 a.m.-11:05 p.m. & $\begin{array}{l}\text { Sat. 8:15 a.m.-10:50 p.m. and } \\
\text { Sun. 9:30 a.m.-7:10 p.m. }\end{array}$ \\
\hline Livonia & $\begin{array}{c}\text { Livonia Community } \\
\text { Transit - } \\
\text { Senior/Disabled } \\
\text { Transportation } \\
\end{array}$ & City & $\mathrm{Y}$ & $\mathrm{N}$ & 2 & Y & 7:00 a.m.-6:30 p.m. & 8:00 a.m.-2:30 p.m. \\
\hline Rochester Hills & OPC Minibuses & City & $\mathrm{Y}$ & $\mathrm{N}$ & 2 & Y & $\begin{array}{l}\text { 8:00 a.m.-5:00 p.m. (last } \\
\text { pick-up at 4:00 p.m.) }\end{array}$ & $\begin{array}{l}\text { Sat. 9:00 a.m.-4:00 p.m. and } \\
\text { Sun. 8:00 a.m.-1:00 p.m. }\end{array}$ \\
\hline Southfield & $\begin{array}{c}\text { TOSS_Transportation } \\
\text { of Southfield } \\
\text { Seniors }\end{array}$ & City & Y & $\mathrm{N}$ & 5 & $\mathrm{~N}$ & 8:00 a.m.-4:00 p.m. & Closed \\
\hline
\end{tabular}


Table 1. Cont

\begin{tabular}{|c|c|c|c|c|c|c|c|c|}
\hline \multirow{2}{*}{ City Name } & \multirow{2}{*}{$\begin{array}{c}\text { Services Program } \\
\text { Name }\end{array}$} & \multirow{2}{*}{$\begin{array}{c}\text { Area } \\
\text { Served }\end{array}$} & \multirow{2}{*}{$\begin{array}{c}\text { Advanced } \\
\text { Notice } \\
\text { Needed } \\
\end{array}$} & \multirow{2}{*}{$\begin{array}{c}\text { Same-Day } \\
\text { Ride }\end{array}$} & \multirow{2}{*}{$\begin{array}{l}\text { Service } \\
\text { Fees } / \$\end{array}$} & \multirow{2}{*}{$\begin{array}{l}\text { Door to } \\
\text { Door } \\
\text { Services }\end{array}$} & \multicolumn{2}{|c|}{ Service Times } \\
\hline & & & & & & & Monday to Friday & Saturday \& Sunday \\
\hline Sterling Heights & $\begin{array}{l}\text { Sterling Heights } \\
\text { Senior Center } \\
\text { Transportation }\end{array}$ & City & $\mathrm{Y}$ & $\mathrm{N}$ & 0 & $\mathrm{~N}$ & 8:30 a.m.-2:30 p.m. & Closed \\
\hline Troy & Medi-Go Plus & City & $\mathrm{Y}$ & $\mathrm{N}$ & 2 & $\mathrm{Y}$ & 8:30 a.m.-4:30 p.m. & Closed \\
\hline Warren & $\begin{array}{l}\text { Center Line \& } \\
\text { Warren Senior } \\
\text { Transportation }\end{array}$ & City & Y & $\mathrm{N}$ & 3 & $\mathrm{~N}$ & 8:00 a.m.-3:00 p.m. & Closed \\
\hline Westland & $\begin{array}{c}\text { FISH Dial-A-Ride of } \\
\text { Western Wayne } \\
\text { County }\end{array}$ & City & $\mathrm{Y}$ & $\mathrm{N}$ & 0 & $\mathrm{~N}$ & Varies & Closed \\
\hline Wyoming & Ridelink & City & Y & $\mathrm{Y}$ & 2 & $\mathrm{Y}$ & 7:30 a.m.-4:30 p.m. & Sun. 8:00 a.m.-2:00 p.n \\
\hline
\end{tabular}


To examine the presence of a statistically significant relationship between transit services and preventive healthcare attainment, we also suspect that socio-economic characteristics such as living arrangement, economic status, and race, as mentioned in the literature, have impacts on attainment of preventive healthcare services among the elderly population. The underlying thought is that lower access to a private vehicle reduces the possibility of preventative healthcare attainment; the financial accessibility indicated by income is also closely related to preventative healthcare attainment; and the non-white population may have low accessibility to healthcare attainment compared with their white counterparts. Therefore, this study further collected data from the U.S. Census and controlled them for these socio-economic factors (i.e., car ownership, poverty rate, race, and disability). Association of variables was tested via OLS regressions in SPSS. All variables were checked for normality (and treated for these if the variables were not normally distributed) and regression models verified the absence of multi-collinearity issues by examining variance inflation factor (VIF) estimates.

Specifically, we wanted to test the following hypotheses:

(1) The presence of transportation services catering specifically to older adults would lead to higher levels of preventive healthcare attainment.

(2) Higher socio-economic levels would lead to higher preventive healthcare attainment.

\section{Results}

This section starts with a summary of the provision of specialized transit services for the older adult population in the selected sixteen cities, as shown in Table 1. We then interpret and discuss the statistical regression outcomes. Finally, we discuss the results of some interviews we undertook with key informants on their opinions on the barriers faced by older adults in maintaining medical appointments.

\subsection{Transit Services for Older Adults by Cities}

Table 1 lists the transportation-related information that we obtained from transit agency websites for each city, and the eligibility requirements that the elderly population need to meet if they want to use the current transit services available in their city. In Table 1, all sixteen cities currently provide their own transit programs that specifically serve the older adult population. Many current transit programs cover the whole city except the city of Lansing. The city of Lansing defines the service areas as three-quarters of a mile from the transit agency's fixed bus routes, which consequently excludes the elderly population who live in the city but not within three-quarters of a mile beyond the extent of the fixed route. Table 1 also shows that current transit programs that specifically serve the elderly in all selected cities require advanced reservations, and almost 70 percent of them (11 out of 16) do not provide transit services for same-day rides. Looking at service types and costs, firstly, transit costs for each trip differ by cities, ranging from zero to five dollars one-way. Secondly, only half of the selected cities ( 8 out of 16) currently provide door-to-door services. In addition, many specialized transit programs for the elderly population only provide transit services during fixed hours on weekdays except in the city of Westland. On weekends, the transit services are limited by hours of operation, if not absent altogether.

\subsection{Regression Outcomes}

Table 2 shows the descriptive statistics of variables used in the regression analyses, while Table 3 shows the regression outcomes of the multi-linear regression models used in the current study. Overall, the regression outcomes suggest that door-to-door services and economic status have statistically significant effects on the attainment of preventive healthcare services. Model 1, which was set up to test the first hypothesis, showed that there is a higher percentage of the older adult population who attain preventive healthcare services in census tracts where door-to-door services are provided, fewer requirements/conditions to ride transit, and the entire area is served by the transit agency. 
Table 2. Descriptive statistics.

\begin{tabular}{|c|c|c|c|c|c|}
\hline Variable & $\mathbf{N}$ & Minimum & Maximum & Mean & $\begin{array}{l}\text { Standard } \\
\text { Deviation }\end{array}$ \\
\hline Area Served * & 731 & 0 & 1 & 0.9904 & 0.0974 \\
\hline $\begin{array}{l}\text { Requirements to Obtain Current } \\
\text { Transit Services ** }\end{array}$ & 731 & 0 & 1 & 0.8864 & 0.3174 \\
\hline Fees (Natural Log) & 681 & 0 & 0.6989 & 0.2165 & 0.2274 \\
\hline Door to Door Services* & 731 & 0 & 1 & 0.3201 & 0.4668 \\
\hline Wheelchair capable * & 731 & 0 & 1 & 0.9233 & 0.2661 \\
\hline Population without Vehicles (\%) & 729 & 0 & 68.88 & 16.5274 & 13.2493 \\
\hline Walkability Score & 729 & 0 & 98 & 42.0493 & 21.3189 \\
\hline $\begin{array}{l}\text { Poverty Ratio among the Elderly } \\
\text { (Natural Log) }\end{array}$ & 686 & 0 & 1.8850 & 1.0437 & 0.4059 \\
\hline Non-White Elderly Population (\%) & 731 & 0 & 100 & 46.4697 & 38.6363 \\
\hline $\begin{array}{c}\text { Elderly Population Who Live } \\
\text { Alone }(\%)\end{array}$ & 724 & 10.4265 & 100 & 67.1161 & 17.0327 \\
\hline $\begin{array}{l}\text { Elderly Population with } \\
\text { Disabilities (\%) }\end{array}$ & 725 & 0 & 100 & 41.8893 & 14.5757 \\
\hline Housing Cost (\%) & 727 & 11 & 100 & 38.3272 & 12.4898 \\
\hline
\end{tabular}

${ }^{*}$ Indicates binary/dummy variable where $1=$ Yes and $0=$ No. ${ }^{* *}$ Indicates binary variable where $1=$ No extra requirements to ride and $0=$ Extra requirements to ride.

Table 3. Multi-linear regression outcomes.

\begin{tabular}{|c|c|c|}
\hline Variable & Model 1 & Model 2 \\
\hline Area Served & 4.2304 * & \\
\hline Eligibility Requirements to Obtain Current Transit Services & $2.6348^{* * *}$ & $1.7356^{* * *}$ \\
\hline Fees & $5.9851^{* * *}$ & \\
\hline Door to Door Services & $4.0303^{* * *}$ & $2.7123^{* * *}$ \\
\hline Wheelchair capable & $-2.1288 *$ & \\
\hline Population without Vehicles (\%) & $-0.2738^{* * *}$ & $-0.0858^{* * *}$ \\
\hline Walkability Score & & $-0.0245^{* * *}$ \\
\hline Poverty Ratio among the Elderly (Natural Log) & & $-2.1086^{* * *}$ \\
\hline Non-White Elderly Population (\%) & & $-0.0707^{* * *}$ \\
\hline Elderly Population Who Live Alone (\%) & & $0.0389^{* * *}$ \\
\hline Elderly Population with Disabilities (\%) & & $-0.0632^{* * *}$ \\
\hline Housing Cost $(\%)$ & & $-0.1219 * * *$ \\
\hline _cons & $25.3746^{* * *}$ & $38.2922^{* * *}$ \\
\hline R-Square & 0.6000 & 0.7568 \\
\hline $\mathrm{N}$ & 679 & 683 \\
\hline
\end{tabular}

In Model 2, where we add the socio-economic characteristics to transportation variables, results indicate that these variables might be more strongly related to the attainment of preventive healthcare than some of the transportation variables. Specifically, variables pertaining to the extent of area served, wheelchair capability, and fare charged become insignificant when socio-economic variables are added to the regression model. The percentage of the elderly population who attain preventive healthcare 
services decreases by 2.11 percent as the poverty rate among the elderly population increases by a one percent. Turning to other demographic and socio-economic factors, notable results indicate car ownership, race, and disability rates calculated for the elderly population are negatively related to the attainment of preventive healthcare services. For example, a one percent increase in the population who do not have access to a private vehicle is associated with a 0.086 percent decrease in the percentage of the elderly population who attain preventive healthcare services.

Figures 3 and 4 visually depict some of the variables for two sample cities (East Lansing and Ann Arbor) to gain a better perspective on the relationships between transportation, socio-economic characteristics, and preventive healthcare attainment. A few factors included in the regression model are also mapped at the census tract level in Figures 3 and 4: the percentage of healthcare attainment among the elderly population, the poverty rate among the elderly population in the natural logarithm type, and the percentage of non-white people among the elderly population. In general, Figures 3 and 4 suggest that at the census tract level (1) higher accessibility to public transit is related to a higher percentage of older adults that attain preventive healthcare services, and (2) a lower poverty ratio is related to a higher percentage of preventive healthcare attainment.

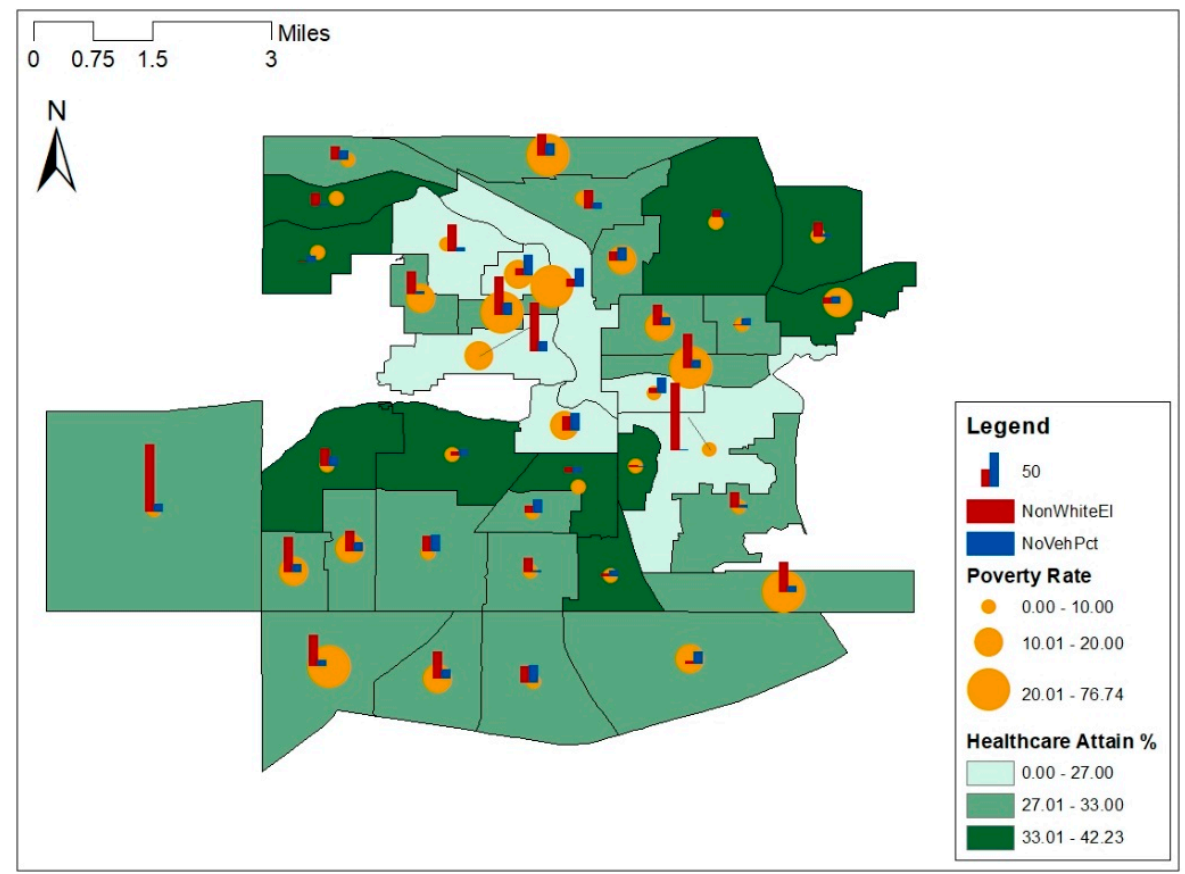

Figure 3. Race, poverty ratio, and healthcare attainment in Lansing. 


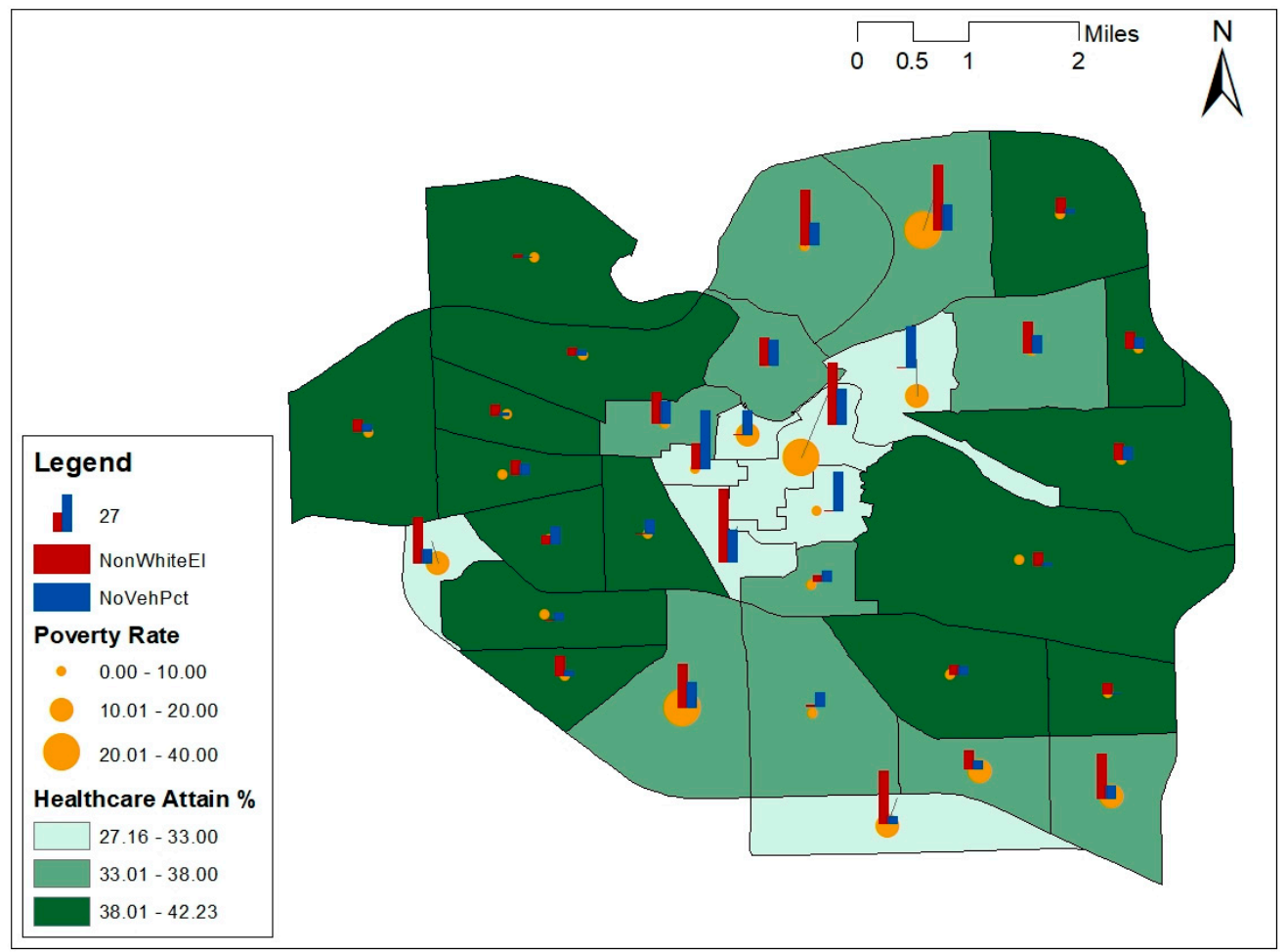

Figure 4. Race, poverty ratio, and healthcare attainment in Ann Arbor.

\subsection{Qualitative Inquiry}

Although the statistical analyses conducted on the provision of transportation and preventive healthcare attainment confirmed our hypotheses, we still believe that objective information from transit agency websites and objective data from the 500 Cities Project did not give us first-hand information as to the reason why some older adults had not attained their preventive healthcare services. Being unable to get in touch with the older adults and ask them directly about the barriers they face getting to medical appointments as the costs of such data acquisition were prohibitive, we turned to the next best approach. Upon attaining Institutional Review Board (IRB) approval, we interviewed a few key informants from Area Agencies on Aging and Transportation coordinators in selected cities that had the lowest and highest levels of healthcare attainment, to understand what they thought the barriers were that older adults in their jurisdiction faced when scheduling rides to get to medical appointments. We thought, since these offices worked closely with older adults and were committed to helping them in various ways, they would be knowledgeable about the challenges that older adults in their jurisdictions were facing.

We contacted the Tri-County Office on Aging (the city of Lansing is in this jurisdiction) first and asked them if they would be willing to answer a few questions on what they knew about why older adults in their jurisdiction might not attain preventive healthcare services, and we were able to interview two key members from this Agency. Thereafter, we asked them to help us get in touch with a few other Area Agencies on Aging, using the snowball method of recruiting a sample for qualitative inquiries. Using this method, we were able to speak with representatives from the Detroit Area Agency on Aging 1-B (the city of Detroit falls in their jurisdiction). We also spoke with key members from the "myride2" [19] program that specifically coordinates transportation for many of the eastern Michigan counties (cities of Troy, Livonia, and Detroit would fall in their jurisdiction). During the interview, we asked what the interviewees thought were the main reasons older adults in their areas might not attain preventive healthcare. We had open conversations that were transcribed by notetakers. Thereafter, we also discussed our results with them to see if the qualitative inquiry matched the quantitative analyses. 
The interview results reveal a myriad of factors that are perceived as barriers to arranging transportation to medical appointments. The main barriers range from scheduling constraints and older adults not being aware of what transit services are available to them in the Lansing region, to costs of rides and traversing transit jurisdictions in the Detroit area. Requiring advanced reservations is found to be a critical barrier to providing suitable transit services for the elderly population to attain preventive healthcare services. Specifically, it becomes much more challenging for the elderly population to use technological tools such as cellphones and personal computers to fill in the complicated documents that are required to complete advanced reservations. This barrier was also echoed by our other key informants.

The Detroit area faces problems of a slightly different nature. The sheer size alone of the older adult population that needs to be served in this area is a factor that complicates issues. Transportation was acknowledged to be a major factor in terms of older adults getting to medical appointments. The need for a consistent and reliable service, combined with a lack of funding to venture into creative solutions to get older adults to their appointments, has an overall negative effect. Transportation coordination is attempted at various levels, but these are in essence "brokers" for this service, which has led to inconsistencies in the actual provision of this service. Other alternatives, such as the "MI choice waiver" [20] program, which is a support program where services come to older adults instead of them going to medical appointments, are available; however, there are income and illness criteria that have to be met for them to avail of these services. One informant stressed that with greater than $50 \%$ of older adults not having transportation covered within their insurance programs, costs of transportation becomes the biggest barrier to getting to doctors' appointments.

Even with transportation options covered through Medicare, many inconsistencies and troubles with the service have been reported, which leads to older adults opting to not use the service. Another factor that consistently came up in the interviews is that medical appointments such as those for dialysis or physical therapy need to be scheduled for multiple times a week, and when cost is a major barrier, these critical appointments get missed. There is long-term value to insurance companies when older adults attain preventive healthcare services, yet this point has not been addressed sufficiently in literature nor consistently in practice. Counties that employ a "senior millage" do not have a lot of the transportation issues most other counties face. One informant summed up the structural deficiency within the transit system, specifically for older adults, by saying: "The system is set up with the expectation that family takes on the burden of transportation for older adults".

On a positive note, all key informants conveyed the critical importance of transportation for older adults in helping them not only get to doctors' appointments but also be more mobile in their communities. On that note, there have been a few instances of grants and funding that have been distributed to areas (Metro Detroit for one) where the main aspect involved is transportation provision specifically for older adults, and the $\$ 8$ Million Michigan Mobility Challenge [21] is one such effort. Some areas like Troy, for example, have a more affluent population base, which helps ease at least one of the main barriers-cost. Volunteer programs fare better in more affluent areas as well. There are also some new health care systems that specifically target older adults and try to eliminate the transportation barrier to medical appointments (Oak Street Health is one example) [22].

\section{Discussion}

This study examined the relationship between transportation services and preventive healthcare attainment for Older Adults in selected cities in Michigan. Essentially, we found that the provision of door-to-door services significantly improves healthcare attainment levels for older adults, a slight variation on Mattson's [6] findings, in which he found that routine healthcare visits in rural areas were not significantly affected by distance and transportation options, but emergency healthcare visits were significantly affected. Further, this study corroborated the findings from Syed, Gerber \& Sharp [16] in that socio-economic characteristics play a major role in preventive healthcare attainment. For example, older adults with lower incomes, non-white racial backgrounds, and without access to a vehicle face 
greater barriers to accessing healthcare than their wealthier, white, and mobile counterparts. Transit services specifically for the elderly need to be further improved, as the fixed-route public transit system is limited and unsuitable for the elderly to attain preventive healthcare because of fixed schedules, walking distances, and poorly provided waiting spots. While the study showed the critical connection between transportation services and preventive healthcare attainment, it also stresses the importance of socio-economic characteristics where health is concerned, specifically for older adults as they were the focus that was often missing in previous literature and studies.

The results make an important contribution to current literature as they indicate a clear divide between cities with higher socio-economic characteristics compared with those on the lower strata where these factors are concerned. Revisiting Figures 1 and 2 shows that the spectrum on which the cities fall for healthcare attainment compares well with that of median household income (see Figure 5). Noteworthy here is the fact that socio-economic status does not align with transportation provision for older adults specifically, as those areas with higher incomes have older adults that are not dependent on public transportation services; rather, they have the capacity/capability to obtain rides through other means (such as taxis). Transportation services become increasingly more important in areas with lower incomes as they tend to be more dependent on public transportation.

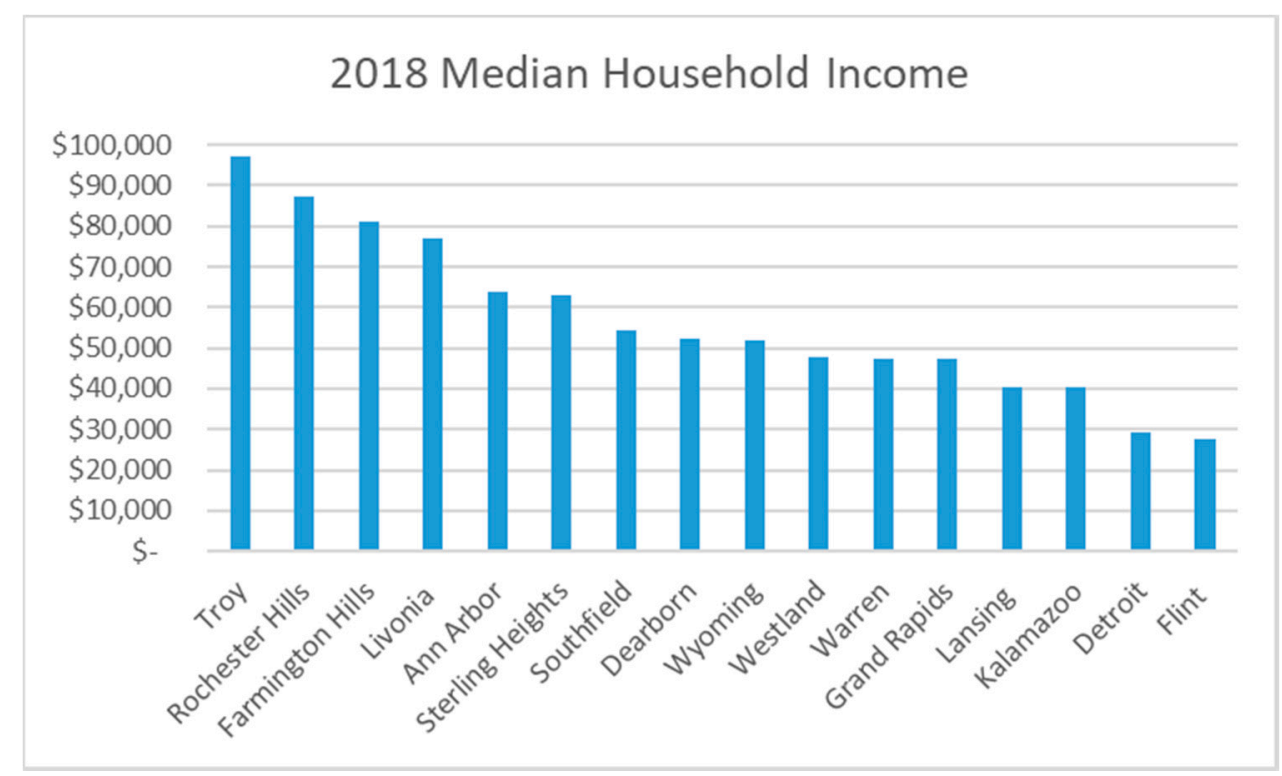

Figure 5. 2018 median household income by city. (Data Source: 2018 American Community Survey).

Another important aspect of this study is that it takes into consideration opinions of stakeholders that work closely with older adults-Area Agencies on Aging. When key people from selected agencies on aging were interviewed, they were able to shed more light on difficulties in terms of transportation and keeping healthcare appointments. Nuances such as working across transit jurisdictions, costs, difficulties with coordinating and booking transportation services, and awareness of benefits associated with particular insurance plans are only able to be brought to attention through such engaged conversations and are not prevalent in any data that are available on the topic.

This study also has some limitations, the main one being that data from public transit agency websites are objective and do not reflect or bring out the nuances of the barriers that older adults face while accessing healthcare facilities. The data that we have are mainly from the supply side, and we do not have information from the older adults themselves on what they perceive the barriers to mobility and accessing healthcare to be, which is why we conducted some interviews with key informants. Future studies could aim to get a complete picture by surveying/interviewing older adults to assess perceived barriers. Secondly, we only look at the effects of transportation on preventive 
healthcare attainment, while there could be other factors that prevent older adults from making doctors' appointments.

\section{Conclusions}

This study makes a few advances in academic research and knowledge despite its limitations. First, using the unique dataset from the 500 Cities Project, we are able to show statistical relationships between transportation and healthcare attainment for older adults. This has been very difficult to do within the social sciences as healthcare data is not easy to obtain, specifically at the geographic level of census tracts. Second, local areas can replicate studies like this to gauge their level of healthcare attainment and the underlying causes to create consistent, effective, and inclusive policies on transportation requirements so that they can better address the needs of the older adult population cohort in their jurisdiction.

Policy implications point to the notion that having consistent transportation services for older adults would help them lead healthier lives. Regional transit planning could take a special look at consistency of coverage, especially for their demand response services as these are services that older adults use most for their daily travel needs. Connections with rideshare companies could help first mile/last mile (FMLM) issues as well as coverage consistency issues. Insurance companies themselves should be willing to forge connections with transit agencies and rideshare companies to bring transportation services to older adults specifically for medical appointments. These would help with increasing preventive care and decreasing hospital/emergency room visits that are much costlier.

This study manages to tie together different aspects of healthcare attainment with the needs of the older adult population. While needs assessments and perceptions are important studies to conduct, empirical testing and modeling through statistical analyses while corroborating nuances through interviews increases focus. In this case, the focus is specifically on the healthcare attainment rate of older adults as a factor relating to transportation provision and is tested for selected cities in the state of Michigan.

Author Contributions: Conceptualization, Z.K.-K. and L.K.; methodology, Z.K.-K.; formal analysis, W.W.; investigation, W.W.; data curation, W.W.; writing-original draft preparation, W.W.; writing-review and editing, L.K. and Z.K.-K.; supervision, L.K. and Z.K.-K.; project administration, Z.K.-K.; funding acquisition, Z.K.-K. All authors have read and agreed to the published version of the manuscript.

Funding: This research was funded by Urban Institute through funds provided by the Robert Wood Johnson Foundation, grant number 101566-0001-MSU-01.

Conflicts of Interest: The authors declare no conflict of interest. The funders had no role in the design of the study; in the collection, analyses, or interpretation of data; in the writing of the manuscript, or in the decision to publish the results.

\section{References}

1. United States Census Bureau. Older Population and Aging. Available online: https://www.census.gov/ topics/population/older-aging.html (accessed on 27 February 2019).

2. Kim, S. Transportation Alternatives of the Elderly after Driving Cessation. Transp. Res. Rec. 2011, 2265, 170-176. [CrossRef]

3. Smith, M.L.; Prohaska, T.R.; MacLeod, K.E.; Ory, M.G.; Eisenstein, A.R.; Ragland, D.R.; Satariano, W.A. Non-Emergency Medical Transportation Needs of Middle-Aged and Older Adults: A Rural-Urban Comparison in Delaware, USA. Int. J. Environ. Res. Pub. Health 2017, 14, 174. [CrossRef] [PubMed]

4. Yang, Y.-T.; Iqbal, U.; Ko, H.-L.; Wu, C.-R.; Chiu, H.-T.; Lin, Y.-C.; Lin, W.; Hsu, Y.-H.E. The relationship between accessibility of healthcare facilities and medical care utilization among the middle-aged and elderly population in Taiwan. Int. J. Qual. Health C 2015, 27, 223-231. [CrossRef] [PubMed]

5. Arcury, T.A.; Preisser, J.S.; Gesler, W.M.; Powers, J.M. Access to Transportation and Health Care Utilization in a Rural Region. J. Rural Health 2006, 21, 31-38. [CrossRef] [PubMed]

6. Mattson, J. Transportation, Distance, and Health Care Utilization for Older Adults in Rural and Small Urban Areas. Transp. Res. Rec. 2011, 2265, 192-199. [CrossRef] 
7. Litman, T. Evaluating Public Transportation Health Benefits; Victoria Transport Policy Institute: Victoria, BC, Canada, 2008; Available online: http://www.vtpi.org/tran_health.pdf (accessed on 10 April 2018).

8. Kotval-K, Z. Transit accessibility for older adults in the Greater Lansing, Michigan region. Qual. Ageing Older Adults 2017, 18, 175-187. [CrossRef]

9. Thakuriah, P.V.; Sööt, S.; Cottrill, C.; Tilahun, N.; Blaise, T.; Vassilakis, W. Integrated and Continuing Transportation Services for Seniors: Case Studies of New Freedom Program. Transp. Res. Rec. 2011, 2265, 161-169. [CrossRef]

10. Battista, G.A.; Lee, B.H.; Kolodinsky, J.; Heiss, S.N. Exploring Transportation Accessibility to Health Care among Vermont's Rural Seniors. Transp. Res. Rec. 2019, 2531, 137-145. [CrossRef]

11. Silver, D.; Blustein, J.; Weitzman, B.C. Transportation to Clinic: Findings from a Pilot Clinic-Based Survey of Low-Income Suburbanites. J Immigr. Minor Health 2012, 14, 350-355. [CrossRef] [PubMed]

12. Wallace, R.; Hughes-Cromwick, P.; Mull, H.; Khasnabis, S. Access to Health Care and Nonemergency Medical Transportation: Two Missing Links. Transp. Res. Rec. 2005, 1924, 76-84. [CrossRef]

13. Kullanit, A.; Taneepanichskul, N. Transportation barriers on healthcare utilization among elderly population living in Mahasarakham province, Thailand. J Health Res. 2017, 31, S233-S238. [CrossRef]

14. Zhang, Q.; Northridge, M.E.; Jin, Z.; Metcalf, S.S. Modeling accessibility of screening and treatment facilities for older adults using transportation networks. Appl. Geogr. 2018, 93, 64-75. [CrossRef] [PubMed]

15. Paez, A.; Mercado, R.G.; Farber, S.; Morency, C.; Roorda, M. Accessibility to health care facilities in Montreal Island: An application of relative accessibility indicators from the perspective of senior and non-senior residents. Int. J. Health Geogr. 2010, 9, 52. [CrossRef] [PubMed]

16. Syed, S.T.; Gerber, B.S.; Sharp, L.K. Traveling Towards Disease: Transportation Barriers to Health Care Access. J Commun. Health 2013, 38, 976-993. [CrossRef] [PubMed]

17. Koehn, S. Negotiating candidacy: Ethnic minority seniors' access to care. Ageing Soc. 2009, 29, 585-608. [CrossRef] [PubMed]

18. Center for Disease Control. Available online: https://www.cdc.gov/500Cities/ (accessed on 10 April 2018).

19. MyRide2. Available online: http://www.myride2.com/ (accessed on 10 April 2018).

20. Michigan Department of Health and Human Services-MDHHS. MI Choice Waiver Program. Available online: https://www.michigan.gov/mdhhs/0,5885,7-339-71547_2943_4857-16263--,00.html (accessed on 27 February 2019).

21. Michigan Department of Transportation-MDOT. \$8 Million Michigan Mobility Challenge. Available online: https://www.michigan.gov/mdot/0,4616,7-151-9621_17216_86614---,00.html (accessed on 27 April 2019).

22. Oak Street Health. Available online: https://www.oakstreethealth.com/ (accessed on 27 February 2019). 